\title{
Clinical Study \\ Prevalence of Chronic Kidney Disease and Its Association with Risk Factors in Disadvantageous Population
}

\author{
Md Nurul Huda, ${ }^{1}$ Kazi Shahnoor Alam, ${ }^{2}$ and Harun-Ur-Rashid ${ }^{3}$ \\ ${ }^{1}$ Department of Nephrology, Chittagong Medical College, Chittagong 4212, Bangladesh \\ ${ }^{2}$ Department of Nephrology, National Institute of Kidney Disease and Urology, Dhaka 1207, Bangladesh
}

${ }^{3}$ Kidney Foundation, Dhaka 1216, Bangladesh

Correspondence should be addressed to Md Nurul Huda, huda23bd@yahoo.com

Received 1 March 2012; Revised 2 May 2012; Accepted 3 May 2012

Academic Editor: Greg Tesch

Copyright ( $) 2012$ Md Nurul Huda et al. This is an open access article distributed under the Creative Commons Attribution License, which permits unrestricted use, distribution, and reproduction in any medium, provided the original work is properly cited.

The prevalence of kidney disease, particularly diabetic and hypertensive kidney disease is increasing rapidly specially in the disadvantageous group of population throughout the world. A cross sectional survey was carried out at certain selected slum areas of Mirpur in Dhaka city of Bangladesh over the period from July 2003 to June 2005, and a total of participants ranging from 15 to 65 years were studied. The analysis discovered that $4.1 \%$ of the participants were diabetic, $11.6 \%$ were hypertensive, and $7.7 \%$ had proteinuria. Based on MDRD equation, $13.1 \%$ of the participants were detected as having chronic kidney disease (CKD) while with Cockcroft-Gault equation 16\% had CKD. Accordingly, the difference between the two equations was not significant. Association of sociodemographic factors with CKD was not significant except age more than 40 years and marital status. The association between CKD and risk factors like proteinuria, obese and overweight, use of tobacco, diabetes mellitus, and hypertension was highly significant. Combined prevalence of DM, hypertension, and proteinuria among CKD group was also demonstrated to be significantly higher (3.8\% with Cockcroft-Gault equation and 5.3\% with MDRD equation) than that of normal population. The survey data revealed that $\mathrm{CKD}$ and its risk factors like DM and hypertension are alarmingly high in disadvantageous population and adding further pressure to the existing burden of CKD.

\section{Introduction}

Chronic kidney disease (CKD) is an ailment of fatality. Accordingly, many people are meeting their dooms around the world by the affliction of this disease. It is miserably factual that we barely perceive any symptom till the collapse takes place. Consequently, most of the time, it seems difficult to prevent the renal failure.

End-stage renal disease (ESRD) has reached epidemic proportion with more than 400,000 affected individuals in the United States and well over one million worldwide [1]. This staggering number represents only the tip of the iceberg, as the incidence of chronic kidney disease (CKD) is at least 30-fold higher than that of ESRD [2].

The incidence of kidney disease, particularly diabetic kidney disease, is increasing rapidly in many disadvantageous populations throughout the world [3]. Disadvantageous populations are socioeconomically unprivileged having limited access to health care and low socioeconomic status related to occupational and educational level.

CKD and the development of ESRD due to type 2 DM and systemic hypertension are particularly common in the minority population in the USA, that is, African American, Hispanic, Asian American, and native [4, 5], who are socioeconomically disadvantageous and may lack health insurance and have limited access to the health care [6]. Renal disease is also increasing, with an age-adjusted incidence of treated ESRD in Australian aboriginals approximately 20 times that of nonaboriginal people and doubling every three to four years [7]. In Sweden, low socioeconomic status related to occupational and educational level is associated with increased risk of chronic renal failure [8].

Staging of CKD is based on estimation of renal function by GFR. GFR is calculated from serum creatinine by 
Cockcroft-Gault and MDRD equations. Some study showed that there were a significant number of patients with normal serum creatinine level who had abnormal GFR with Cockcroft-Gault values $\leq 50 \mathrm{~mL} / \mathrm{min}$ [9]. This group of patients may remain unrecognized by primary care physicians who rely on serum creatinine abnormality to identify renal insufficiency.

With the increase of diabetes and hypertension, the prevalence of chronic kidney disease (CKD) is also alarmingly going up particularly in disadvantageous population. We conducted this study among the urban disadvantageous population to find out the prevalence of CKD and its association with risk factors as there was no exact data before this tiny endeavor that has been inaugurated in Bangladesh.

\section{Materials and Methods}

This cross-sectional survey was carried out at certain selected slum areas of Mirpur at Dhaka city in Bangladesh over the period from July 2003 to June 2005. A multistage clustered sampling design following a simple random sampling procedure was done to choose the study area (Mirpur slums), and a total of 1000 participants ranging from 15 to 65 years had been studied. Out of the chosen 1000 respondents, 666 were females and 334 were males.

Inclusion criteria.

Age between 15 and 65 years irrespective of sex.

Exclusion criteria.

(1) Age below 15 years and above 65 years.

(2) Condition when albumin excretion is increased-exercise, pregnancy, and fever.

(3) People who did not provide consent to participate.

Variables studied were age, sex, marital status, occupation, family income, literary status, body weight (in kilogram), height (in centimeter), and body mass index $(\mathrm{BMI})=$ weight in $\mathrm{kg} /$ height in $\mathrm{m}^{2}$.

Risk factors studied were diabetes mellitus, hypertension, tobacco use, overweight and obesity, and proteinuria detected by multistick.

Participants were categorized by BMI as per WHO criteria into normal (BMI 18.5-24.9), under weight (<18.5), overweight (25.0-29.9), obese (30.0-39.9), and morbid obese $(\geq 40.00)$.

Participants were considered to have diabetes mellitus if previously they had been recognized by the doctor as having DM or any documents in favour of DM or they reported taking insulin or oral antidiabetic drug or random plasma glucose $\geq 11.1 \mathrm{mmol} / \mathrm{L}$ with symptom. Hypertension was defined as systolic $\mathrm{BP} \geq 140 \mathrm{mmHg}$ or diastolic $\mathrm{BP} \geq$ $90 \mathrm{mmHg}$ or use of medication for hypertension irrespective of the blood pressure.

A random urine sample of MSU (midstream urine) had been collected from each participant using a clean catch technique and sterile container. Urinary excretion of protein and sugar was detected by multisticks named "Uripath 5" made in the UK.

Serum creatinine was measured by alkaline picrate method (Jaffe kinetic assay), which was not standardized by IDMS. Serum creatinine was determined as $\mu \mathrm{mol} / \mathrm{L}$ and converted to $\mathrm{mg} / \mathrm{dl}$ by conversion factor 88.4 [10]. Ccr (creatinine clearance rate) and estimated GFR (glomerular filtration rate) were calculated from serum creatinine $(\mathrm{mg} / \mathrm{dL})$ by using Cockcroft-Gault and MDRD (modification of diet in renal disease) equations.

Equations Developed to Predict GFR in Adult Based on Serum Creatinine. (1) Cockcroft-Gault equation (1976)

$$
\operatorname{Ccr}(\mathrm{mL} / \mathrm{min})=\frac{(140 \text {-age }) \times \text { Weight }(\mathrm{Kg})}{72 \times \mathrm{S} . \text { creatinine }(\mathrm{mg} / \mathrm{dL})} \times 0.85 \text { if female }
$$

(2) Original MDRD equations (2000) estimated GFR = $186.3 \times(\text { S. creatinine })^{-1.154} \times(\text { age })^{-0.203} \times 0.742($ if female $)$.

Normalization of Ccr or GFR for Body Surface Area (BSA). Normalization of Ccr for BSA allows more accurate evaluation of renal function. Traditionally, $1.73 \mathrm{~m}^{2}$ is used as standard BSA. As in our population average BSA is low, it needs to be corrected by $1.73 /$ BSA [11]:

$$
\text { Ccr corrected by BSA }=\frac{\operatorname{Ccr}(\mathrm{mL} / \mathrm{min}) \times 1.73 \mathrm{~m}^{2}}{\mathrm{BSA}\left(\mathrm{m}^{2}\right)} \text {. }
$$

Body surface area can be determined from height and weight using a monogram found in standard references:

$$
\operatorname{BSA}\left(\mathrm{m}^{2}\right)=\sqrt{\frac{\text { Height }(\mathrm{cm}) \times \text { weight }(\mathrm{Kg})}{3600}} .
$$

CKD staging was done according to K/DOQI guideline 2002. Stage 1 includes GFR $\geq 90 \mathrm{~mL} / \mathrm{min}+$ proteinuria. Stage 2 includes GFR $60-89 \mathrm{~mL} / \mathrm{min}+$ proteinuria. Stage 3 includes GFR $30-59 \mathrm{~mL} / \mathrm{mil} \pm$ proteinuria. Stage 4 includes GFR $15-$ $29 \mathrm{~mL} / \mathrm{min} \pm$ proteinuria. Stage 5 includes $\mathrm{GFR}<15 \mathrm{~mL} / \mathrm{min}$ or dialysis \pm proteinuria.

All the participants with CKD screened at the 1st visit were advised to have their serum checked for creatinine and urine for protein 3 months after the first check-up.

Data were collected using structured questionnaire and were finalized after field testing. Software "SPSS" and software "EpiInfo 2000" have been used for data processing and analysis. Test statistics used to analyze the data were "Chisquare test," and "Fisher's exact test" and $P$ values less than 0.05 were considered significant. There was no incentive for the slum population (respondents), and an ethical clearance was taken from departmental committee.

\section{Observations and Results}

The analysis showed that $55 \%$ of the participants were young and early-middle-aged (from 15-40 years of age) while the 


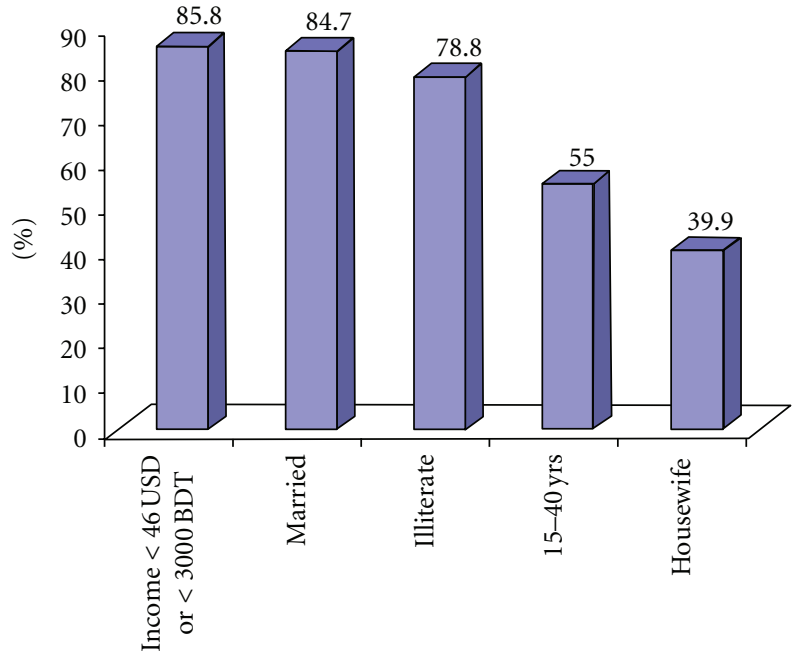

Sociodemographic characteristics

FIgURe 1: Dominant sociodemographic characteristics of the participants.

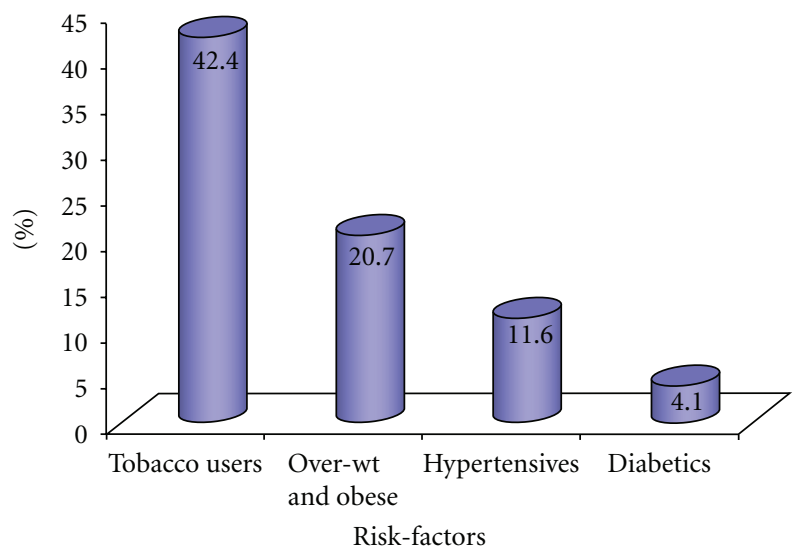

Figure 2: Distribution of participants by risk factors: The commonest risk-factor was use of tobacco $42.4 \%$ either as smoking or chewing or both. $11.6 \%$ was hypertensive, $4.1 \%$ was diabetics and $20.7 \%$ was over-wt and obese $\left(\mathrm{BMI} \geq 25 \mathrm{~kg} / \mathrm{M}^{2}\right)$.

mean age was $34.39( \pm 12.70)$ years. A female preponderance was observed among the participants $(66.6 \%)$. The majority of the participants were married $(84.7 \%)$ and illiterate $(78.8 \%)$, and $85.8 \%$ had monthly income $<3000$ Taka (approximately USD 46) (Figure 1). In terms of occupation, the housewives comprised the main bulk (39.9\%) followed by garment-workers $17.4 \%$, small-business $9.4 \%$, service $9 \%$, day laborers $5.4 \%$, rickshaw-puller $4.3 \%$, and other jobs $10.6 \%$. The rest of $4 \%$ was unemployed. BMI study categorized $57.5 \%$ of the participants as normal, $21.8 \%$ as underweight, $17.4 \%$ as overweight, $3 \%$ as obese, and $0.3 \%$ as morbidly obese. Out of the 1000 participants, $116(11.6 \%)$ were hypertensive. Of them 50 (43.1\%) were self-reported and $66(56.9 \%)$ were diagnosed during the survey. Out of 41 (4.1\%) diabetics, 20 (48.7\%) were known and $21(51.3 \%)$ were identified during the survey (Figure 2).
TABLE 1: CKD staging by different equations $(N=1000)$.

\begin{tabular}{lcc}
\hline Staging of CKD & Cockcroft-Gault & MDRD \\
\hline Total CKD & $\mathbf{1 6 0 ( 1 6 . 0 ) ^ { * }}$ & $\mathbf{1 3 1 ( 1 3 . 1 )}$ \\
Stage 1 & $13(1.3)$ & $27(2.7)$ \\
Stage 2 & $34(3.4)$ & $39(3.9)$ \\
Stage 3 & $\mathbf{1 0 9}(\mathbf{1 0 . 9})$ & $\mathbf{6 3}(\mathbf{6 . 3})$ \\
Stage 4 & $3(0.3)$ & $1(0.1)$ \\
Stage 5 & $1(0.1)$ & $1(0.1)$ \\
Normal & $\mathbf{8 4 0 ( 8 4 . 0 )}$ & $\mathbf{8 6 9}(\mathbf{8 6 . 9})$ \\
\hline
\end{tabular}

${ }^{*}$ Figures in the parentheses denote corresponding \%.

Urine albumin analysis using multisticks demonstrated that $7.7 \%$ of the participants had proteinuria, of them $5.7 \%$ had "+" proteinuria, 1.6\% had "++" and $0.4 \%$, had " +++ " proteinuria.

Out of the total population, $1.3 \%$ of the males had serum creatinine $>1.5 \mathrm{mg} / \mathrm{dL}$ and $2.7 \%$ of the female had serum creatinine $>1.3 \mathrm{mg} / \mathrm{dL}$, comprising $4 \%$ participants with raised serum creatinine.

The mean Ccr by Cockcroft-Gault equation was $85.1 \mathrm{~mL} / \mathrm{minute}$ in males and $99.2 \mathrm{~mL} /$ minute in females, while the mean eGFR by MDRD equation was $100.8 \mathrm{~mL} /$ minute in males and $133 \mathrm{~mL} /$ minute in females.

Out of the 1000 participiants, 13.1\% were identified as CKD by MDRD equation and $16 \%$ by Cockcroft-Gault equation. Stage 3 CKD was most dominant; $10.9 \%$ in $\mathrm{C}-\mathrm{G}$ equation and $6.3 \%$ in MDRD equation. The prevalence of CKD did not differ significantly between the two methods (C-G and MDRD equation) of staging $(P=0.687$ ) (Table 1$)$.

The middle-aged and elderly (from 41 to 65 years) population tend to develop CKD more than the young and early middle-aged population (from 15 to 40 years of age) $(P<0.001)$. Married groups $(93.9 \%)$ also demonstrate a higher predilection to develop CKD than their unmarried counterparts $(83.3 \%)(P<0.05)$. Other variables were almost homogeneously distributed in both CKD and normal population (Table 2).

All the riskfactors, except BMI (overweight and obese), were present in significant proportions in CKD group compared to the normal populations $(P<0.001, P<0.001, P<$ 0.001, $P<0.05$, and $P<0.05)$ when Cockcroft-Gault equation was used. More than one-quarter $(25.6 \%)$ of the CKD participiants were overweight and obese compared to $19.6 \%$ of those without CKD although the difference between the two groups did not reach the level of significance $(P=0.086)$ (Table 3$)$.

Apart from the use of tobacco, all other variables were highly prone to be associated with $\mathrm{CKD}(P<0.001)$ when MDRD equation was used. Though use of tobacco was comparatively high in CKD group than that of normal population, the difference was not big enough to be statistically significant $(P=0.059)$ (Table 4$)$. 
TABLE 2: Association between CKD (MDRD equation) and sociodemographic variables.

\begin{tabular}{|c|c|c|c|c|}
\hline \multirow{2}{*}{ Socio-demographic variables } & \multicolumn{2}{|c|}{ Group } & \multirow{2}{*}{$x^{2}$ value } & \multirow{2}{*}{${ }^{*} P$ values } \\
\hline & $\mathrm{CKD} \%(n=131)$ & Normal \% $(n=869)$ & & \\
\hline Middle-aged and elderly (age $>40$ yrs) & 54.2 & 22.2 & 59.95 & $<0.001$ \\
\hline Sex (female) & 62.6 & 67.2 & 1.087 & 0.297 \\
\hline Occupation (housewives) & 44.3 & 39.2 & 0.304 & 0.142 \\
\hline Income $(\leq 2000 \mathrm{BDT}$ or USD $\leq 30)$ & 56.3 & 59.0 & 0.304 & 0.581 \\
\hline Literacy (illiterate) & 77.9 & 78.9 & 0.79 & 0.778 \\
\hline Marital status (married) & 93.9 & 83.3 & 9.83 & 0.002 \\
\hline
\end{tabular}

${ }^{*}$ Data were analysed using Chi-squared $\left(\chi^{2}\right)$ test, and level of significance was 0.05. $d f=1$.

TABLE 3: Association of CKD (Cockcroft-Gault equation) with risk-factors.

\begin{tabular}{|c|c|c|c|c|}
\hline \multirow{2}{*}{ Risk factors } & \multicolumn{2}{|c|}{ Group } & \multirow{2}{*}{$x^{2}$ value } & \multirow{2}{*}{${ }^{*} P$ values } \\
\hline & CKD \% $(n=160)$ & Normal \% $(n=840)$ & & \\
\hline Over-wt and obese $\left(\mathrm{BMI} \geq 25 \mathrm{~kg} / \mathrm{M}^{2}\right)^{\#}$ & 25.6 & 19.6 & 2.94 & 0.086 \\
\hline Use of tobacco ${ }^{\#}$ & 58.1 & 39.4 & 19.28 & $<0.001$ \\
\hline $\mathrm{DM}$ (self-reported $+\mathrm{RBS}>11.1 \mathrm{mg} / \mathrm{dL})^{\#}$ & 10.6 & 2.9 & 20.62 & $<0.001$ \\
\hline HTN (self-reported + newly diagnosed) & 31.9 & 7.7 & 76.35 & $<0.001$ \\
\hline Combined DM and HTN* & 3.8 & 0.6 & 8.71 & 0.004 \\
\hline Combined DM, HTN, and proteinuria* & 2.5 & 0.4 & 6.209 & 0.015 \\
\hline
\end{tabular}

\# Data were analysed using Chi-squared $\left(\chi^{2}\right)$ test.

* Data were analysed with the help of Fisher's exact test; level of significance was 0.05 .

$d f=1$.

\section{Discussion}

The present study conducted for "detection of chronic kidney disease and its association with risk factors in disadvantageous population" is the first ever study done in the slum area of Dhaka in Bangladesh that has urban disadvantageous population. Slum or disadvantageous population differs from other common people of Bangladesh in terms of income (average monthly income approximately USD 46), educational level (78.8\% illiterate), and receiving health care facility. The prevalence study was done to examine the prevalence of diabetes mellitus, hypertension, and chronic kidney disease (based on proteinuria and low GFR) and to find the association of CKD with sociodemographic and other alleged risk factors.

We found $4.1 \%$ of the participants were diabetic and $11.6 \%$ were hypertensive in our study. The crude prevalence of type-2 DM in different communities in Bangladesh is $4.3 \%$ in rural population [12], $7.9 \%$ in urban population [13], and $8.1 \%$ in urban slums of Dhaka [14]. The prevalence of hypertension in rural population of Bangladesh with systolic blood pressure (SBP) $\geq 140 \mathrm{mmHg}$ was $10.5 \%$ and with diastolic blood pressure (DBP) $\geq 90 \mathrm{mmHg}$ was 9\% [15] and prevalence of hypertension in urban slum population of Dhaka was $15 \%$ and $16.7 \%$, respectively [14].

Urine protein analysis using multisticks demonstrated that $7.7 \%$ of the participants had proteinuria. Two previous population-based studies had examined the prevalence of proteinuria in adults. Iseki et al. [16] detected proteinuria that was defined by a dipstick result of trace or greater in 4 to $6 \%$ of men and 2.5 to $7 \%$ of women in a study of $1,07,192$ Japanese volunteers. A similar prevalence ranging from 1\% in 34-44-year-old to 6\% in 55-64-year-old men was found in the US volunteers in Framingham study [17] though dipstick detection of proteinuria has better sensitivity than specificity.

Prevalence of CKD in the present survey was $13.1 \%$ when MDRD equation was used, out of which stage 3 (GFR 30$59 \mathrm{~mL} / \mathrm{min}$ ) was dominant (6.3\%). Prevalence of CKD using MDRD in the US adult population was $11 \%$, out of which stage 1 was $3.3 \%$, stage $23 \%$, stage $34.3 \%$, stage $4(0.2 \%)$ and stage $50.2 \%$ [10].

Prevalence of CKD in this survey was $16 \%$ when Cockcroft-Gault equation was used, out of which stage 3 was $10.9 \%$. Prevalence of CKD using C-G equation in AusDiab kidney study was also $16 \%$ [18]. The prevalence of CKD stage 3 to 5 was greater using $\mathrm{C}-\mathrm{G}$ equation than MDRD equation (7\% versus $4.5 \%$ ) [10]. 12.9\% of Japanese individuals were predicted to have CKD (using MDRD) of them stage 3 was $10.4 \%$ [19].

No significant difference was found in the proportion of CKD whether C-G equation or MDRD equation was used. Similar report has also been shown in NHANES III data when age of the population is less than 65-70 years. Thus the study data suggest that detection of CKD is not dependent on the method of CKD staging.

We also showed that raised serum creatinine was present in $4 \%$ of our study population in terms of sex. Kidney early 
TABLE 4: Association of CKD (MDRD Equation) with risk factors.

\begin{tabular}{lcccc}
\hline \multirow{2}{*}{ Risk factors } & \multicolumn{2}{c}{ Group } & $x^{2}$ value & $*{ }^{*}$ values \\
\hline Over-wt and obese $\left(\mathrm{BMI} \geq 25 \mathrm{~kg} / \mathrm{M}^{2}\right)^{\#}$ & 47.3 & Normal $\%(n=869)$ & 65.84 & $<0.001$ \\
Use of tobacco & 48.9 & 16.6 & 2.57 & 0.059 \\
DM (self-reported + RBS $>11.1 \mathrm{mg} / \mathrm{dL})^{\#}$ & 16.8 & 41.4 & 61.77 & $<0.001$ \\
HTN (self-reported + newly diagnosed) ${ }^{\#}$ & 38.9 & 7.2 & 109.81 & $<0.001$ \\
Combined DM and HTN* & 6.1 & 0.3 & 20.86 & $<0.001$ \\
Combined DM, HTN, and proteinuria $^{*}$ & 5.3 & 0 & 28.78 & $<0.001$ \\
\hline
\end{tabular}

${ }^{\#}$ Data were analysed using Chi-squared $\left(\chi^{2}\right)$ test.

$*$ Data were analysed with the help of Fisher's exact test; level of significance was 0.05 .

$d f=1$.

evaluation program (KEEP) demonstrated that $5 \%$ of the entire KEEP population had raised serum creatinine, $>1.5 \mathrm{mg} / \mathrm{dL}$ in males and $>1.3 \mathrm{mg} / \mathrm{dL}$ in females [20].

Association of demographic factor with CKD showed that age $>40$ years was significantly prone to developing CKD compared to age $<40$ years whatever the equations were used $(P<0.001)$. In Iceland study, AusDiab kidney study, and US prevalence study 3rd National Health and Nutrition Examination survey (NHANES III) demonstrated similar results of increased CKD with increasing age in both sexes. High prevalence of stage $3 \mathrm{CKD}$ among Thai individuals aged $\geq 35$ was estimated to be about $20 \%$ by using C-G formula and about $13 \%$ by using MDRD equation [21]. The overall prevalence of CKD stages 3 to 5 in Chinese adults aged 35-74 years was lower (2.53\%) when using MDRD equation [22].

Chronic kidney disease (CKD) was not found to be associated with sex $(P>0.05)$ in our targeted respondents. AusDiab kidney study demonstrated the risk of stage 3 to 5 CKD was greater in women $(P=0.002$ for difference between genders). The prevalence of CKD was also higher in females (12.5\%) than males (7\%) in Iceland study.

In our research, CKD is more prevalent in overweight and obese population. Both males and females with low GFR $(<60 \mathrm{~mL} / \mathrm{min})$ had higher BMI than that of control in the Iceland study [23]. Obesity, a component of syndrome $\mathrm{x}$, explains the simultaneous increase in metabolic, cardiovascular, and renal diseases in Australian Aboriginal people [24].

The present study found that use of tobacco in the form of smoking and chewing was significantly higher in CKD group than in the normal population. Ejerblad et al. (2004) suggested that heavy cigarette smoking increased the risk of chronic renal failure for both men and women, at least CRF classified as nephrosclerosis and glomerulonephritis [25]. Among patients with DM and hypertension, smoking seems to be an independent risk factor for nephropathy, which accelerates the progression of renal failure [26-28].

In this study, diabetes mellitus and hypertension were present in significant proportions in CKD group compared to the normal population $(P<0.001)$. Combined prevalence of DM, HTN, and proteinuria in the survey in CKD group was also demonstrated to be significantly higher than that in normal population. The prevalence of CKD stage 3 to 5 was threefold higher in those with DM compared with those without DM $(P<0.001)$ [18]. The AusDiab kidney study demonstrated that reduced GFR $<60 \mathrm{~mL} / \mathrm{min} / 1.73 \mathrm{~m}^{2}$ was fivefold more prevalent in those with hypertension compared to those without HTN $(P<0.001)$. The association of decreased kidney function using Cockcroft-Gault equation with hypertensive and diabetic individuals was similar to decreased kidney function using the MDRD equation [10]. Two hundred diagnosed cases of DM and/or HTN were reviewed by the clinical pharmacists in primary care clinics of Columbus, $\mathrm{OH}$. They demonstrated a total of $68.9 \%$ who met CKD criteria, indicating that CKD prevalence was high among the hypertensive and/or diabetic patients [29]. Besides, renal disease is also increasing in Australian aboriginals who have serious comorbidities, reflecting their poor health of them in general, including poor nutrition, infections, uncontrolled diabetes, and hypertension [30].

\section{Conclusion}

The survey data vividly revealed that CKD is present in no less than $13 \%$ and raised serum creatinine is $4 \%$ among the urban disadvantageous population of slum area. The commonest risk factors for CKD like DM and hypertension are also alarmingly high and obviously adding to the existing burden of CKD. The association between CKD and other risk factors like age, obese and overweight, use of tobacco, DM, and HTN was also highly significant. When more than one risk factor was present, the chance of developing CKD was extensively eminent. The present study, therefore, proposes that a nationwide survey is inevitable and suggests to be conducted encompassing the entire cross-section of population to find out the prevalence of CKD and its associated risk factors, so that a preventive strategy or an entire defensive framework could be adopted or planned to reduce the disease in the community. Besides, large portion of Bangladeshi people live with extreme poverty and are alienated from the light of education. Hence, their concern about diseases is not sufficient and most of them are not capable of bearing the expenditure of treatment. Nevertheless, it is true that adopting intervention at early stages of CKD can save a family and the entire nation as well from an intense catastrophe. 


\section{Abbreviations}

CKD: Chronic kidney disease

DM: Diabetes mellitus

HTN: Hypertension

BMI: Body mass index

C-G: Cockcroft-Gault formula

MDRD: Modification of diet in renal disease equation

ESRD: End-stage renal disease

Ccr: Creatinine clearance rate

GFR: Glomerular filtration rate.

\section{Conflict of Interests}

The authors declare that there is no conflict of interests.

\section{Acknowledgments}

The authors express their thanks to the staff of Kidney Research Lab of BSMMU for their active cooperation in carrying out different tests and Bangladesh Kidney Foundation for partial funding. Finally, they are sincerely placing their candid honor to the humble respondents and unprivileged slum people of Bangladesh who, they believe, were the main inspiration of this work and it is only their spontaneous participation and response that has made the research evident.

\section{References}

[1] S. G. Satko, B. I. Freedman, and S. Moossavi, "Genetic factors in end-stage renal disease," Kidney International, vol. 67, no. 94, pp. S46-S49, 2005.

[2] C. A. Jones, G. M. McQuillan, J. W. Kusek et al., "Serum creatinine levels in the US population: Third National Health and Nutrition Examination Survey," American Journal of Kidney Diseases, vol. 32, no. 6, pp. 992-999, 1998.

[3] R. G. Nelson, "Intrauterine determinants of diabetic kidney disease in disadvantaged populations," Kidney International, vol. 63, no. 83, pp. S13-S16, 2003.

[4] A. A. S. Lopes, K. Hornbuckle, S. A. James, and F. K. Port, "The joint effects of race and age on the risk of endstage renal disease attributed to hypertension," American Journal of Kidney Diseases, vol. 24, no. 4, pp. 554-560, 1994.

[5] C. C. Cowie, F. K. Port, R. A. Wolfe, P. J. Savage, P. P. Moll, and V. M. Hawthorne, "Disparities in incidence of diabetic endstage renal disease according to race and type of diabetes," The New England Journal of Medicine, vol. 321, no. 16, pp. 10741079, 1989.

[6] K. Fiscella, P. Franks, M. R. Gold, and C. M. Clancy, "Inequality in quality: addressing socioeconomic, racial and ethnic disparities in health care," Journal of the American Medical Association, vol. 283, no. 19, pp. 2579-2584, 2000.

[7] E. H. Wendy, M. Rees, E. Kile, J. D. Mathews, and Z. Wang, "A new dimension to the Barker hypothesis: low birthweight and susceptibility to renal disease," Kidney International, vol. 56, no. 3, pp. 1072-1077, 1999.

[8] C. M. Fored, E. Ejerblad, J. P. Fryzek et al., "Socio-economic status and chronic renal failure: a population-based casecontrol study in Sweden," Nephrology Dialysis Transplantation, vol. 18, no. 1, pp. 82-88, 2003.
[9] L. Duncan, J. Heathcote, O. Djurdjev, and A. Levin, "Screening for renal disease using serum creatinine: who are we missing?" Nephrology Dialysis Transplantation, vol. 16, no. 5, pp. 10421046, 2001.

[10] J. Coresh, B. C. Astor, T. Greene, G. Eknoyan, and A. S. Levey, "Prevalence of chronic kidney disease and decreased kidney function in the adult US population: Third National Health and Nutrition Examination Survey," American Journal of Kidney Diseases, vol. 41, no. 1, pp. 1-12, 2003.

[11] J. C. Verhave, R. T. Gansevoort, H. L. Hillege, D. De Zeeuw, G. C. Curhan, and P. E. De Jong, "Drawbacks of the use of Indirect estimates of renal function to evaluate the effect of risk factors on renal function," Journal of the American Society of Nephrology, vol. 15, no. 5, pp. 1316-1322, 2004.

[12] M. A. Sayeed, H. Mahtab, P. A. Khanam et al., "Diabetes and impaired fasting glycemia in a rural population of Bangladesh," Diabetes Care, vol. 26, no. 4, pp. 1034-1039, 2003.

[13] M. A. Sayeed, L. Ali, M. Z. Hussain, M. A. K. Rumi, A. Banu, and A. K. A. Khan, "Effect of socioeconomic risk factors on the difference in prevalence of diabetes between rural and urban populations in Bangladesh," Diabetes Care, vol. 20, no. 4, pp. 551-555, 1997.

[14] M. A. Rahim, S. Vaaler, S. M. Keramat Ali, A. K. A. Khan, A. Hussain, and Q. Nahar, "Prevalence of type 2 diabetes in urban slums of Dhaka, Bangladesh," Bangladesh Medical Research Council Bulletin, vol. 30, no. 2, pp. 60-70, 2004.

[15] M. A. Sayeed, A. Banu, A. R. Khan, and M. Z. Hussain, "Prevalence of diabetes and hypertension in a rural population of Bangladesh," Diabetes Care, vol. 18, no. 4, pp. 555-558, 1995.

[16] K. Iseki, C. Iseki, Y. Ikemiya, and K. Fukiyama, "Risk of developing end-stage renal disease in a cohort of mass screening," Kidney International, vol. 49, no. 3, pp. 800-805, 1996.

[17] W. B. Kannel, M. J. Stampfer, W. P. Castelli, and J. Verter, "The prognostic significance of proteinuria: the framingham study," American Heart Journal, vol. 108, no. 5, pp. 1347-1352, 1984.

[18] S. J. Chadban, E. M. Briganti, P. G. Kerr et al., "Prevalence of kidney damage in Australian adults: the AusDiab kidney study," Journal of the American Society of Nephrology, vol. 14, no. 2, pp. S131-S138, 2003.

[19] E. Imai, M. Horio, T. Watanabe et al., "Prevalence of chronic kidney disease in the Japanese general population," Clinical and experimental nephrology, vol. 13, no. 6, pp. 621-630, 2009.

[20] W. W. Brown, R. M. Peters, S. E. Ohmit et al., "Early detection of kidney disease in community settings: the kidney early evaluation program (KEEP)," American Journal of Kidney Diseases, vol. 42, no. 1, pp. 22-35, 2003.

[21] V. Perkovic, A. Cass, A. A. Patel et al., "High prevalence of chronic kidney disease in Thailand," Kidney International, vol. 73, no. 4, pp. 473-479, 2008.

[22] J. Chen, R. P. Wildman, D. Gu et al., "Prevalence of decreased kidney function in Chinese adults aged 35 to 74 years," Kidney International, vol. 68, no. 6, pp. 2837-2845, 2005.

[23] O. Viktorsdottir, R. Palsson, M. B. Andresdottir, T. Aspelund, V. Gudnason, and O. S. Indridason, "Prevalence of chronic kidney disease based on estimated glomerular filtration rate and proteinuria in Icelandic adults," Nephrology Dialysis Transplantation, vol. 20, no. 9, pp. 1799-1807, 2005.

[24] W. E. Hoy, J. D. Mathews, D. A. Mccredie et al., "The multidimensional nature of renal disease: rates and associations of albuminuria in an Australian Aboriginal Community," Kidney International, vol. 54, no. 4, pp. 1296-1304, 1998.

[25] E. Ejerblad, C. M. Fored, P. Lindblad et al., "Association between smoking and chronic renal failure in a nationwide 
population-based case-control study," Journal of the American Society of Nephrology, vol. 15, no. 8, pp. 2178-2185, 2004.

[26] S. R. Orth, "Effects of smoking on systemic and intrarenal hemodynamics: influence on renal function," Journal of the American Society of Nephrology, vol. 15, no. 1, pp. S58-S63, 2004.

[27] S. R. Orth, "Smoking-a renal risk factor," Nephron, vol. 86, no. 1, pp. 12-26, 2000.

[28] M. Regalado, S. Yang, and D. E. Wesson, "Cigarette smoking is associated with augmented progression of renal insufficiency in severe essential hypertension," American Journal of Kidney Diseases, vol. 35, no. 4, pp. 687-694, 2000.

[29] H. R. Patel, M. C. Pruchnicki, and L. E. Hall, "Assessment for chronic kidney disease service in high-risk patients at community health clinics," Annals of Pharmacotherapy, vol. 39, no. 1, pp. 22-27, 2005.

[30] W. E. Hoy, "Renal disease in Australian Aboriginals," Medical Journal of Australia, vol. 165, no. 3, pp. 126-127, 1996. 


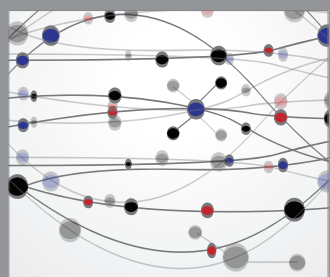

The Scientific World Journal
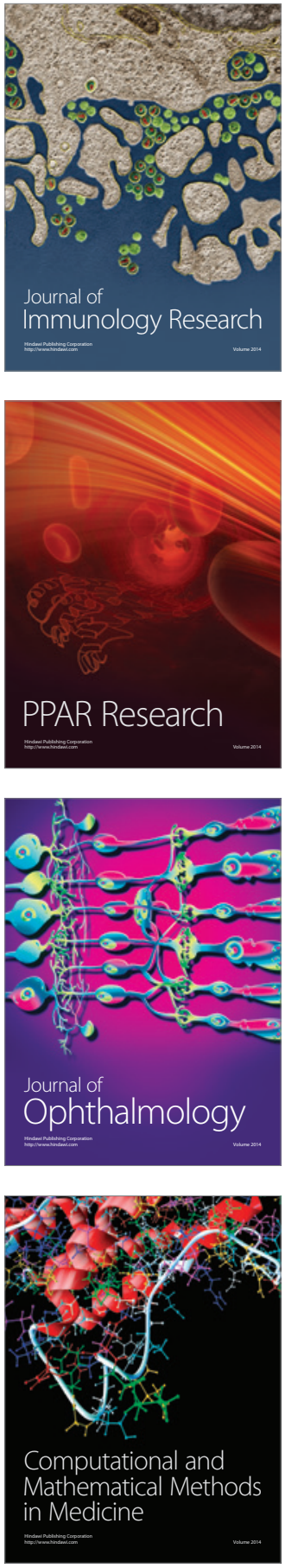

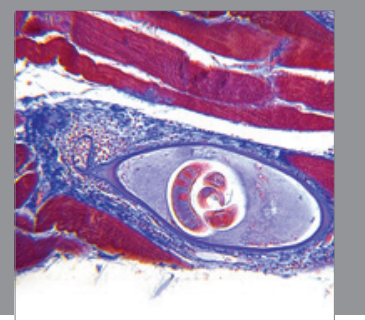

Gastroenterology

Research and Practice
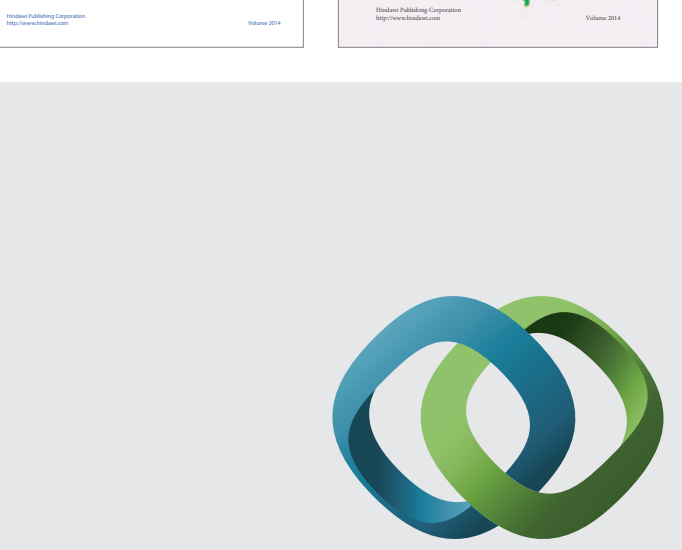

\section{Hindawi}

Submit your manuscripts at

http://www.hindawi.com
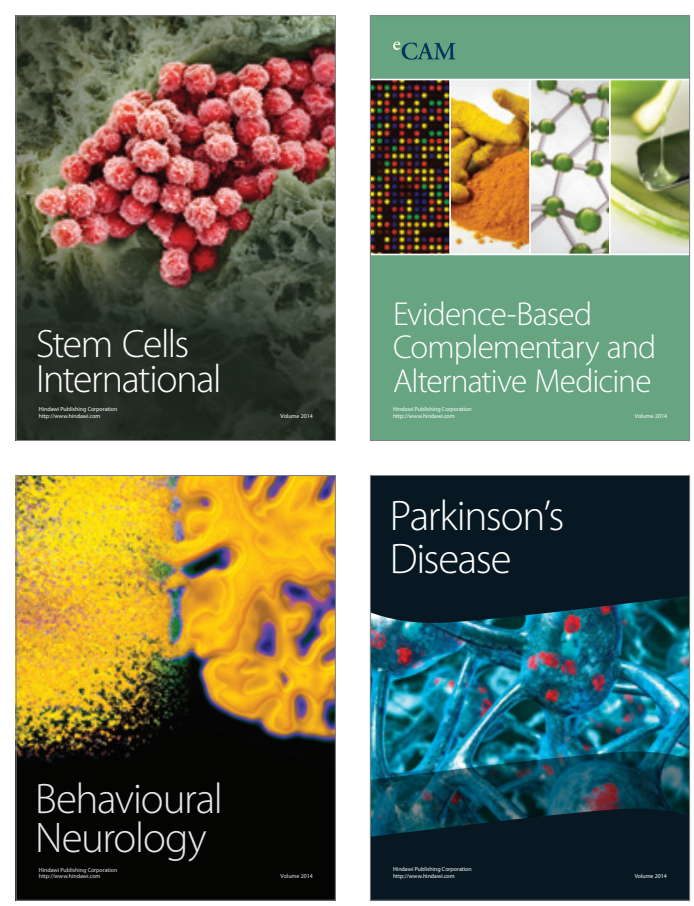

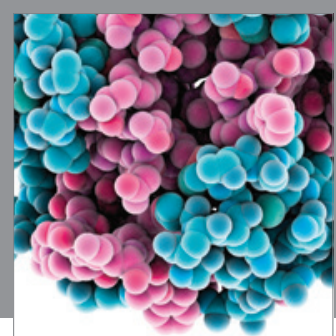

Journal of
Diabetes Research

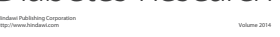

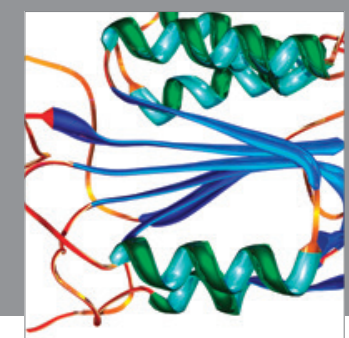

Disease Markers
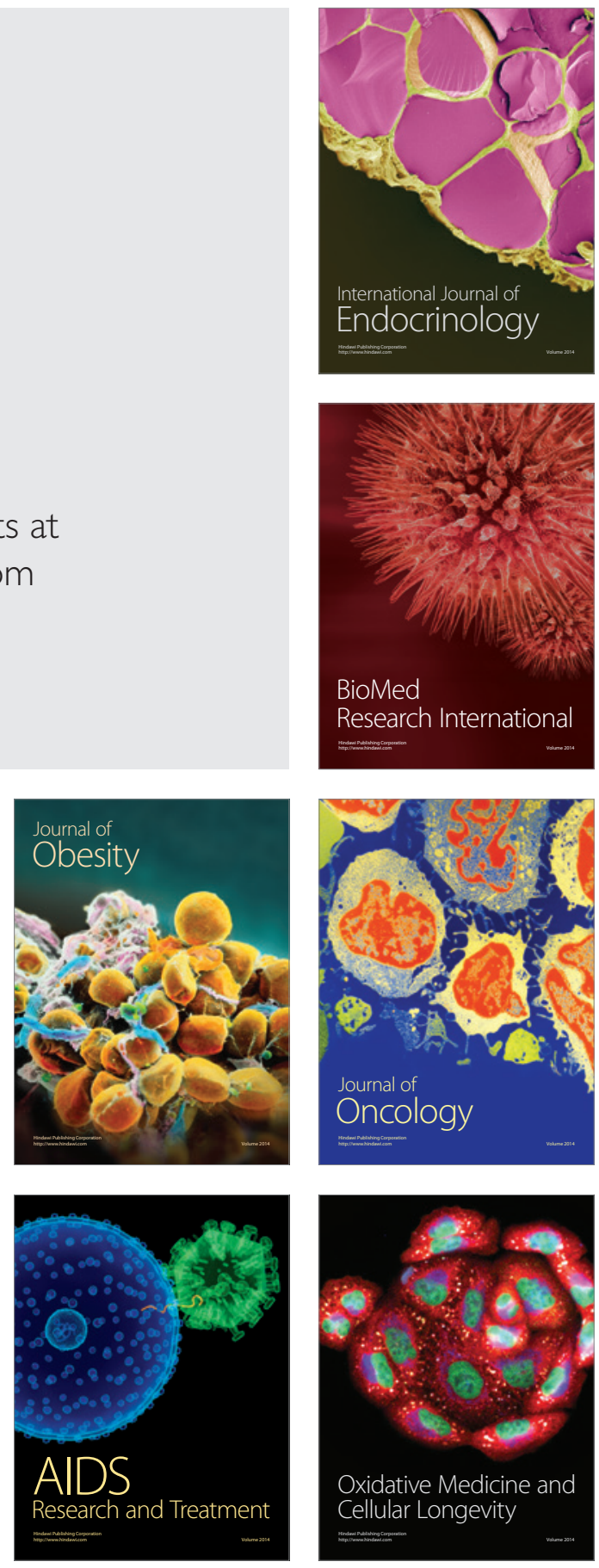